\title{
O USO DO PERFIL GEOECOLÓGICO DA ALDEIA INDÍGENA KYIKATÊJÊ COMO PROPOSTA NO ENSINO DE GEOGRAFIA FÍSICA
}

\author{
Elson Pereira de Almeida ${ }^{(\mathrm{a})}$, Melry Carla Alves Ribeiro ${ }^{(\mathrm{b})}$, Maria Rita Vidal $^{(\mathrm{c})}$ \\ (a) Graduando em Licenciatura em Geografia/ ICH/Faculdade de Geografia, Universidade Federal do Sul e \\ Sudeste do Pará. E-mail: elson@unifesspa.edu.br \\ (b) Graduanda em Licenciatura em Geografia/ ICH/Faculdade de Geografia, Universidade Federal do Sul e \\ Sudeste do Pará, E-mail: melry1995.bm@gmail.com \\ (c) Doutora em Geografia/ ICH/Faculdade de Geografia, Universidade Federal do Sul e Sudeste do Pará, E- \\ mail: ritavidal@unifesspa.edu.br
}

\section{EIXO: GEOGRAFIA FÍSICA - CURRÍCULO, FORMAÇÃO E PRÁTICAS DE ENSINO}

\section{Resumo}

O perfil geoecológico constitui-se como uma técnica de interpretação integrada das condições ambientais, sendo esta uma ferramenta para análises e diagnósticos sobre a paisagem. $\mathrm{O}$ presente trabalho tem por objetivo apresentar o perfil geoecológico da aldeia indígena Kyikatêjê como uma proposta de ensino de geografia na referida aldeia. Sendo elaborado com a o auxílio e uso das tecnologias de informações geográficas, o software CorelDraw como ferramenta de edição e elaboração do desenho para se construir o perfil geoecológico. A contribuição do perfil se mostra como auxilio para construção de materiais didáticos a serem utilizados nas aulas de geografia física na escola da respectiva aldeia. A elaboração do perfil geocologico possibilitou uma análise mais precisa da paisagem local e a compreensão da dinamica natural e social, subsidiando futuros trabalhos no ensino de geografia física.

Palavras chaves: Paisagem; perfil geoecológico; meio ambiente; ensino de geografia.

\section{Introdução}

Estima-se que vivem hoje cerca de duzentos grupos indígenas no Brasil, povos esses que historicamente têm sido vítimas de usurpação territorial, sendo alvos de cobiças pelos recursos naturais que abrigam em seus territórios, fato esse que compromete sua sobrevivência física e cultural. Os procedimentos de mapeamento e a elaboração de perfis geoecológicos são ferramentas úteis para a sistematização, interpretação, comunicação e aprendizado. O etnomapeamento se apresenta como uma ferramenta de diálogo intercultural, podendo ser este útil no ensino de geografia. A representação espacial de uma dada área é o ponto de partida para examinar os processos de mudanças no meio, sendo este uma ferramenta direta para o trabalho didático em sala de aula indígena, se constituindo ainda como importante meio para a gestão dos territórios e compreensão do meio onde se vive. O perfil geoecológico é definido como representação vertical da paisagem consistindo na distinção das feições paisagísticas a ela intrínseca, isso facilita a correlação da leitura dos elementos naturais da paisagem. Sendo assim, uma ferramenta útil na análise da paisagem e no ensino de geografia. A Geoecologia das Paisagens fundamenta à construção do perfil geoecológico, que segundo Rodriguez, Silva e Cavalcanti (2004) a Geoecologia das Paisagens reveste-se de fundamental importância no 
âmbito de uma nova perspectiva, onde as ideias da multidisciplinaridade valorizam a questão ambiental.

Ainda na concepção de Rodriguez, (1994) a Geoecologia da Paisagem é entendida como base para o planejamento ecológico do território, será analisado como um sistema de métodos, procedimentos e técnicas de investigação, cujo propósito consiste na obtenção de um conhecimento sobre o meio natural.

A partir da elaboração de perfis geoecológicos é possível representar cartograficamente secções de determinado espaço geográfico e fazer correlações entre os geo-elementos de interesse (topografia, vegetação, temperatura, pedologia, estrutura geológica, etc.) representados por transectos que compõem o perfil. Como estes transectos são distribuídos de maneira sequencial, às informações (horizontais ou verticais) podem ser integradas para interpretar as condições ambientais atuais de determinado local ao longo do perfil. (LEVIGHIN; VIADANA 2003). De acordo com Rodriguez, Silva e Cavalcanti (2004), a Geoecologia da Paisagem pode enquadrar-se "[...] como uma ciência ambiental, que oferece uma contribuição essencial no conhecimento da base natural do meio ambiente, entendido como meio global", sendo a cartografia e a elaboração de perfis geoecológicos um instrumento importante para a caracterização da paisagem.

Nesta abordagem, a paisagem é analisada como um sistema integrado dotado de objetos naturais e objetos antrópicos, considerando-a um "sistema total". De acordo com Rodriguez et al. (1995), na paisagem, componentes naturais e antropo-naturais interagem em diversas escalas temporo-espaciais.

Desta forma, uma ferramenta útil na análise da paisagem é a construção do perfil geoecológico, elaborado a partir da construção do modelo digital do terreno (MDE) e da observação em campo. Sendo uma técnica de representação da paisagem do mesmo modo que se representa a realidade nos mapas e nos modelos digitais. Porém, se por um lado temos os modelos digitais representando as variações das superfícies e mapas com características da paisagem de forma horizontais o perfil se pauta em ser a representação das características da paisagem em sua forma vertical. A importância da utilização de perfis geoecológicos nos estudos das paisagens e no emprego dessa ferramenta para embasar o ensino de geografia foi discutido por Mascarenhas e Vidal (2013). Muitos trabalhos têm apontados diversos tipos de perfis, que levam em consideração a temática de seus estudos, como perfil geoecológico (MONTEIRO, 2000), perfil biogeográfico ou geológico (TROPPMAIR, 1995), perfil com ou sem topografia (FURLAN, 2009), perfil fitossociológico (DINIZ; FURLAN, 1998) e perfil fisionômico da vegetação (SANTOS, 2004) demonstrando a importância da apresentação do perfil para o entendimento e representação das paisagens. Este trabalho tem por objetivo apresentar o perfil geoecológico da Aldeia Kyikatêjê como uma proposta de ensino de geografia na Escola Estadual Indígena de Ensino Fundamental e Médio Tatakti Kyikatêjê. 
A utilização de mapas e perfis transversais é uma velha prática na Geografia Física, assessorando os trabalhos de campo e a compreensão da análise integrada da paisagem. As várias formas de aplicabilidades de representação por mapas e perfis têm o objetivo de extrair o máximo de elementos da paisagem por meio da análise qualitativa em campo, que constitui um instrumento que auxiliará na compreensão e entendimento nos estudos das paisagens e da geografia na aldeia. A elaboração do perfil possibilitará a base para a construção de materiais didáticos para serem utilizados nas aulas de ensino de geografia física na escola da referida aldeia, levando um maior entendimento dos aspectos físicos-naturais e antrópicos que envolvem a aldeia e suas áreas de entorno. E ainda servirá de apoio na implementação e na elaboração de metodologias no ensino de geografia física e no estudo da paisagem. Para a Região Sudeste do Pará, verificou-se a ausência de estudos com enfoque na Geoecologia das Paisagens, onde uma das ferramentas principais se efetiva através da elaboração do perfil geoecológico. A construção de perfis geoecológicos embasará novos estudos da paisagem local e regional, bem como possibilitará abrir uma nova linha de pesquisa cientifica que verse sobre os sistemas sócio-ecológicos na Sudeste do Pará com enfoque na Geoecologia das paisagens.

\section{Metodologia}

\subsection{Caracterização da área de estudo}

Para compreender a forma como fora desenvolvido o perfil geoecológico, é necessário conhecer a área onde será elaborado. A Terra indígena (TI) Mãe Maria situa-se no Município de Bom Jesus do Tocantins na Região sudeste do Pará, ao longo da BR 222, tem uma área de 62.488 hectares, abrangendo inicialmente três povos indígenas: Parkatêjê, Akrãtikaêjê e os Kyikatêjê (RICARDO, 1985). O povo indígena Kyikatêjês enfrentam em sua reserva, impactos ambientais de toda ordem, a Terra Indígena é constantemente invadida por pessoas de fora, para a coleta de frutos, retirada de madeira, outro impacto importante é causado pela erosão ocasionadas pelos não-indígenas nas fazendas no entorno da aldeia, fragmentação de habitats, influenciando na dispersão e colonização das espécies, além dos impactos diretos gerados pela construção da BR-222 e implantação da linha de alta tensão, ambas cortam a Terra indígena em questão. A Terra Indígena Mãe Maria, fica distante da cidade de Marabá-PA aproximadamente 30Km, inserida na Região Hidrográfica Tocantins-Araguaia, a Terra Mãe Maria é limitada a oeste pelo rio Flexeiro e a leste pelo rio Jacundá, a reserva é drenada ainda pelo rio Mãe Maria. Atualmente (2016) existem aproximadamente 13 aldeias independentes dentro da Terra Mãe Maria, entre elas a aldeia Kykatêjê, onde foi desenvolvido o perfil em função dos trabalhos pesquisa e extensão em andamento na referida aldeia, ver figura 1. 


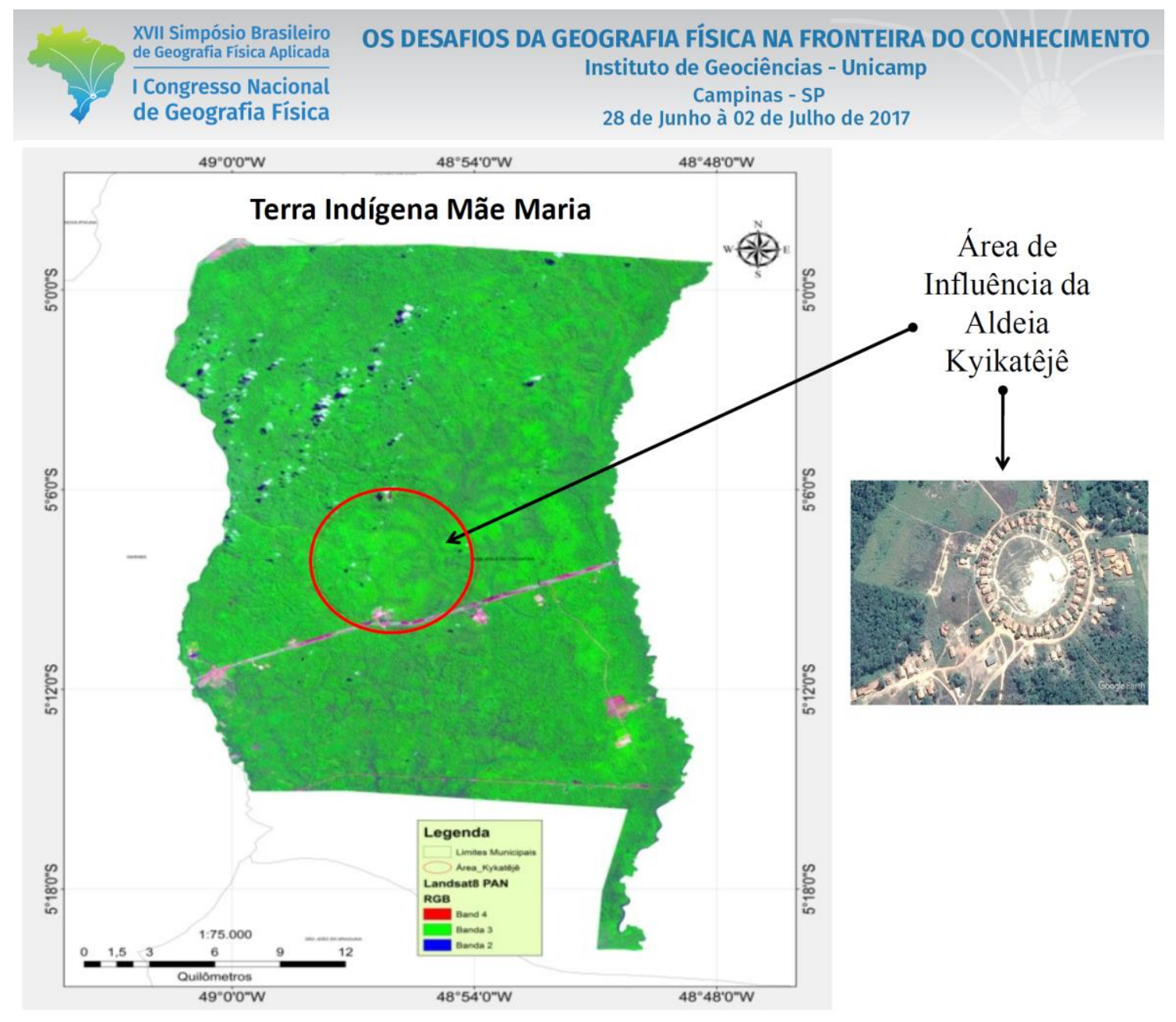

Figura 1- Localização Geográfica da Terra Indígena Mãe Maria e a área da aldeia Kyikatêjê. Fonte: Vidal, 2017.

A Aldeia indígena kyikatêjê localiza-se as margens da BR 222, desmembrada da aldeia Parkateje em 2001, se mostra atualmente com elevado grau de organização e gestão política, sendo a educação escolar como parte do projeto de autodeterminação dos Kyikatêjê.

\subsection{Elaboração do MDE seus atributos topográficos e a elaboração do perfil}

A elaboração do Modelo Digital de Elevação (MDE) que permite uma visualização mais próxima da realidade, o modelo digital de elevação foi confeccionado a partir das imagens SRTM v.4 cenas: SRTM-26;27 do consórcio para a informação espacial-CGIAR-CSI, interpolada por Jarvis, Nelson e Guevara (2008). Seu método possibilitou preencher dados de superfícies irregulares dando uma aproximação da realidade modelada, assim é que, no presente trabalho, foram extraídas curvas de nível em intervalos de 20 metros, das quais foram úteis para definir os atributos topográficos e confeccionar o perfil geoecológico. De posse das altitudes e rugosidades do terreno, obtido através do MDE, dar-se continuidade a elaboração do perfil. Para tanto, essa ação só é possível com a realização do trabalho de campo para que sejam levantados os aspectos físicos naturais da aldeia, assim como a identificação dos principais impactos negativos ocorridos na área e seu entorno com a coleta de pontos georreferenciados. As anotações são importantes e pertinentes à estrutura, às dinâmicas e aos processos atuantes na área da aldeia. A elaboração de perfil geoecológico requer o conhecimento 
prévio dos componentes naturais, (geologia, geomorfologia, solos, vegetação, hidrografia e clima), parâmetros que dão a introdução aos conceitos e aspectos gerais da situação ambiental, desde uma visão geográfica e também propiciando um entendimento que abarca algumas interrelações entre os diferentes componentes geográficos. Para a elaboração do perfil geoecológico, precisou-se da utilização do software CorelDraw X-8 como ferramenta de edição, o que permite ao pesquisador manipular ferramentas básicas de desenho para construir o perfil, isso pode ser melhorada com as ferramentas de cores, bem como de adição ou construção de vetores/figuras esquemática que podem traduzir certa dinâmica em Campo. Ressalta-se que pela carência de metodologias nesta área do conhecimento (no que diz respeito a confecção dos perfis geoecológicos) esta fora descrita por Mascarenhas e Vidal (2013).

\subsection{Proposta metodológica e o projeto na escola Kyikatêjê}

Como ponto de partida faz-se necessário o fortalecimento do encontro dos sujeitos sociais, momento de mobilização da Escola Estadual Indígena Tatakti Kykatêjê, tendo em vista a aproximação das áreas de conhecimento e da melhoria da formação do aluno. Para tanto, faz-se necessário também o contato com a direção pedagógica, bem como com os professores de geografia que leciona nas turmas do $7^{\circ} \mathrm{e}$ $8^{\circ}$ período para que haja o planejamento das atividades conjuntas. O trabalho desenvolvido pelos pesquisadores tem como proposta a apresentação do perfil geoecológico como uma ferramenta de análise e estudos aos alunos da escola indígena kyikatêjê. Para tanto, a imagem (perfil geoecológico da aldeia) é válida no ensino de geografia, pois leva os alunos indígenas a perceberem nuances no seu espaço vivido. Facilitando o conhecimento deixando-o mais didático e em alguns momentos mais lúdico, despertando o interesse dos discentes. O sistema de ensino vigente pautado em modelos genéricos e fechados, não admitem formas diferenciadas de pensar a educação indígena.

\section{Resultados e Discussão}

A partir da elaboração do MDE, foi possível elaborar o perfil geoecológico da aldeia indígena Kyikatêjê,onde foram delimitadas e caracterizada as unidades geoambientais levando em consideração os elementos geomorfológico, pedológicos e cobertura vegetal - esses elementos foram caracterizados pelas suas estruturas físico-ambientais levantadas em trabalho de campo. O levantamento dos aspectos físicos naturais foi auxiliado com uso planilhas, imagens Landsat8 e por coletas de pontos de GPS. Esse levantamento e caracterização setorizada dos ambientes físicos permitiram a integração dos dados na produção do perfil geoecológico (Figura 2). 


\section{OS DESAFIOS DA GEOGRAFIA FÍSICA NA FRONTEIRA DO CONHECIMENTO Instituto de Geociências - Unicamp Campinas - SP \\ 28 de Junho à 02 de Julho de 2017}

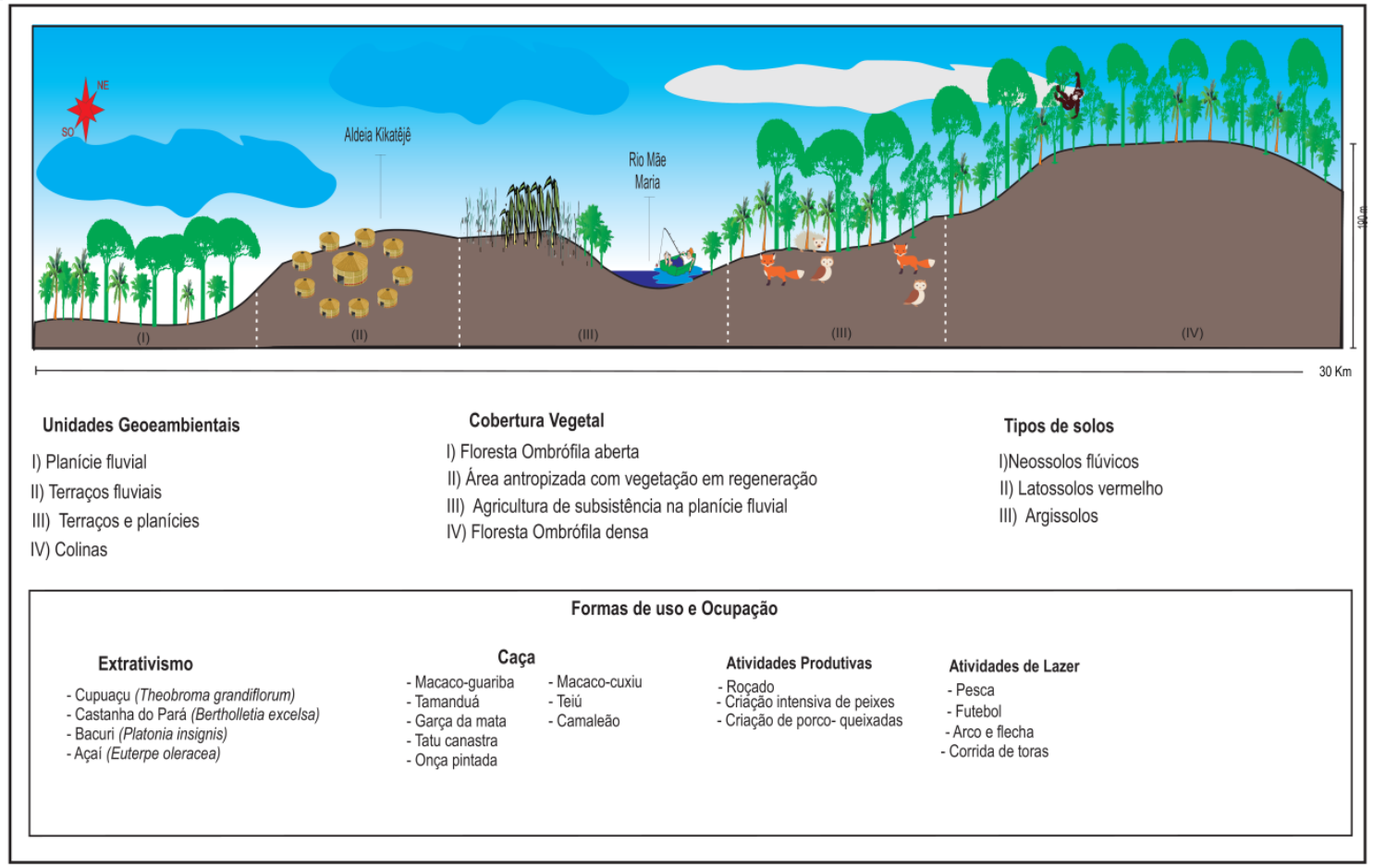

Figura 2. Perfil geoecológico com as formas de uso e ocupação na aldeia indígena Kykatêjê-PA. Fonte: Elaboração dos autores.

O perfil geoecológico realizado na Aldeia indígena kykatêjê demonstra a interação entre a paisagem e as formas de uso e ocupação desenvolvidas na aldeia. Possibilita ainda, perceber a a espacialização dos atributos ambientais, (relevo, hidrografia, solos, vegetação), sendo uma ferramenta útil no planejamento da paisagem e no ensino de geografia.

\section{Formas de uso e ocupação na aldeia Kykatêjê}

As áreas de coletas e extrativismos encontram-se em ( $I$ e IV), tendo a coleta de frutos principais pontuadas por: Cupuaçu (Theobroma grandiflorum), a Castanha do Pará (Bertholletia excelsa). Pela característica física-natural da Terra indígena, o extrativismo dos frutos se constitui uma das principais atividades para os Kykatêjê. A produção se envolve em torno destes frutos, principalmente a castanha que inclusive passa por sérios problemas, pois, tem-se percebido que a produção deste fruto tem diminuído exponencialmente, devido os problemas ambientais ocorrido nesta área. Segundo Fernandes (2010), no ano de 2002, as lideranças Kyikatêjê contrataram uma ONG (Organização Não Governamental) denominada Extensão Amazônica para administrar os recursos repassados pela Companhia Vale do Rio Doce (CVRD), que repassavam como indenização referente aos impactos causados implantação da estrada de ferro que corta a TI. Sendo que esta ONG não conseguiu levar adiante sua administração devido terem interferido diretamente na liderança tradicional deste povo, o que acabou ocorrendo a expulsão deste órgão pelos próprios indígenas e estes tomaram posse da Asociação Kyikatêjê Amtati. 


$\begin{gathered}\text { XVII Simpósio Brasileiro } \\ \text { de Geografia Fisica Aplicada }\end{gathered}$
$\begin{aligned} & \text { I Congresso Nacional } \\ & \text { de Geografia Física }\end{aligned}$

Em (II) encontra-se a aldeia e suas configurações, composta pelas casas, a escola, campo de futebol (ressalta-se que este grupo foram os primeiros a formarem um clube de futebol indígena do Brasil) e também a associação. No processo de autogestão os Kyikatejês tomaram a responsabilidade de administrar associação da aldeia, sendo a contratação de profissionais indígenas com experiências nas atividades em saúde, educação e desenvolvimento de projetos sustentáveis para o trabalho de assessoramento da comunidade e da associação, uma forma de estruturar as ações políticas e organizativas da aldeia (FERNANDES, 2010). Além disso, é importante observar que a criação desta associação foi justamente para servir como instrumento jurídico de representação e encaminhamento das reivindicações e demandas das lideranças Kyikatêjê nas mais diversas instâncias governamentais e não governamentais o que inclui principalmente as suas relações com a Vale.

Em (III) é a área de produção agrícola com o cultivo de milho, mandioca, feijão, também encontra-se a criação de animais como porcos, e o desenvolvimento da atividade de piscicultura em tanques. É nessa unidade que se encontra o Rio Mãe Maria que dá nome a toda a Terra indígena. Nessa unidade ainda encontra-se as áreas de caça, possuindo uma variedade de animais, tais como, a onça pintada (Panthera onca), macaco-guariba (Alouatta), macaco-cuxiu (Chiropotes satanas), tamanduá (Myrmecophaga tridactyla), garça da mata (Agamia agami) e tatu canastra (Priodontes maximus),

\section{Teiu (Tupinambis merianae)}

Em (IV), destaca-se as áreas de extensa pela cobertura vegetal, sendo ainda utilizada para a extração de frutos, são áreas de coleta parcialmente coincidentes com as áreas de caça, o que mostra a relação de interdependência entre as espécies vegetais e animais. Como coleta estão as espécies de Cupuaçu (Theobroma grandiflorum), Castanha do Pará (Bertholletia excelsa), acrescenta-se nesta área, espécies de Açaí (Euterpe oleracea) e Bacuri (Platonia insignis) e coletas de tabocas - usadas na produção de flechas e de madeira para a produção das pontas das flechas.

No tocante as práticas culturais na aldeia pontuam-se a permanência de valores pelos mais velhos $e$ que ainda se pratica nas áreas de mata o exercício do arco e flecha, embora as comunidades indígenas venham sofrendo com o processo de aculturamento ainda é possível verificar as práticas antigas como referência da cultura dos povos Kyikatêjê, Figura 3.

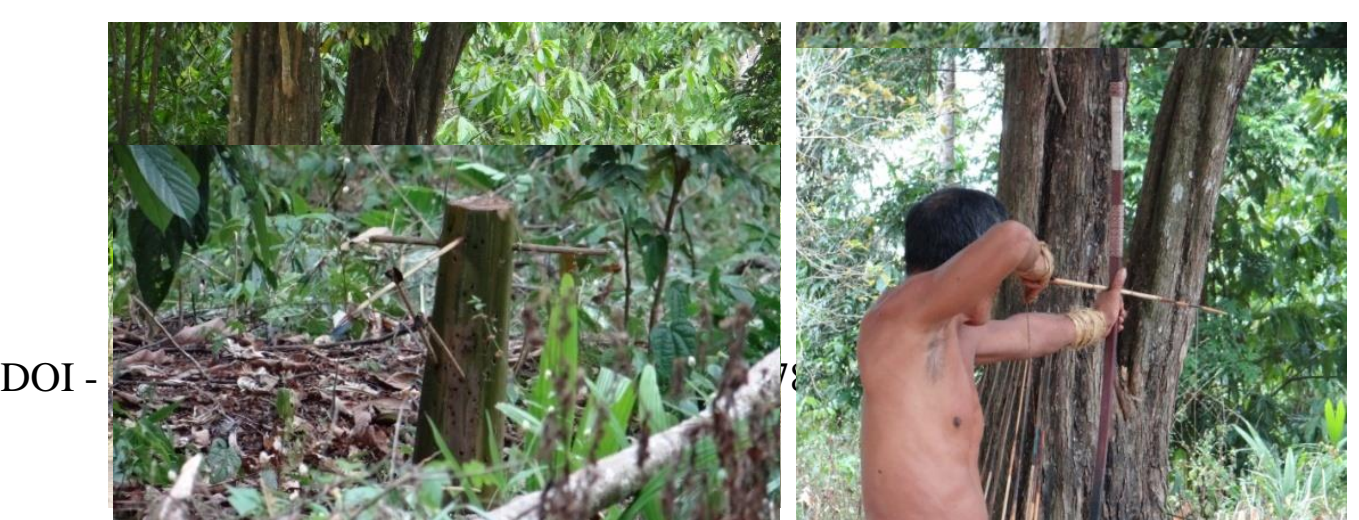


Figura 3 - Índios Kyikatêjê praticando atividade de arco e flecha nas áreas de matas.

Foto: Maria Rita Vidal, 2016.

A atividade de arco e flecha é praticada apenas pelos mais velhos da aldeia, aos poucos essa atividade está ficando somente sobre o saber dos mais antigos. As concepções da Geoecologia das Paisagens possibilita que se apreenda e compreenda qual o grau de transformação realizada pela sociedade humana nos sistemas ambientais, sobretudo no que se refere as Terras indígenas, pois a percepção, interpretação e concepção nas formas de uso e de gestão são reflexos dessa complexa materialização das ações no espaço geográfico. Através do perfil geoecológico a proposta da análise dos aspectos físicos é a transposição deste conteúdo cientifico para o ensino de geografia física, fazendo deste um recurso didático de incentivo à utilização de instrumentos de intervenção pedagógica, como por exemplo, a localização. Além disto, requer como resultado deste trabalho o fortalecimento do ensino de geografia física na aldeia Kyikatêjê, despertando o conhecimento das formas e das representações sobre o meio natural pelos alunos. O desenvolvimento da percepção dos alunos sobre a existência de áreas vulneráveis, degradação, impactos e áreas potenciais na aldeia, dentre outras formas, possibilita um maior entendimento do ensino de geografia. A utilização de perfil como instrumento didático na escola se mostra eficaz no delimitar de cada ponto observado, rascunhado, delimitado, na precisão os elementos contidos na área da aldeia, como por exemplo, no plantio, caça, coletas, etc. Elementos como este que só é possível compreender a partir da vivência, da percepção do seu lugar caracterizando desenvolvimento desse trabalho não pelo entendimento do pesquisador, mas principalmente enfocando no conhecimento particular e a percepção que os alunos indígenas possuem do espaço geográfico.

\section{Conclusão}

A elaboração de perfil geoecológico na aldeia Kyikatêjê, se constitui de suma importância na compreensão e na dinâmica da paisagem local. Desta forma, a construção de perfis geoecológicos embasará novos estudos da paisagem local e regional, subsidiando ações futuras relacionadas ao 
ensino de geografia física voltada para a escola de ensino indígena. Visualiza-se a expectativa é que esse trabalho possa contribuir posteriormente para a construção de materiais didáticos que servirão como apoio nas aulas de geografia física, para que os alunos indígenas obtenham uma melhor compreensão do seu lugar e da paisagem de sua aldeia, possibilitando que os mesmo percebam a dinâmica em que os elementos da paisagem estão envolvidos. Dessa forma, A metodologia para elaboração de perfis se bem empregada em campo pode possibilita um processo de análise mais acurada da Paisagem.

\section{REFERÊNCIAS}

DINIZ, A.; Furlan, S. A. Relações entre classificações fitogeográficas, fitossociologia, cartografia, escalas e modificações sócio-culturais no parque estadual de campos do jordão. In: Revista do Departamento de Geografia, FFLCH-USP, São Paulo, n 12, p. 123-61. 1998.

FURLAN, S. A. Técnica de Biogeografia. In: VENTURI, L. A. B. (Org.) Praticando Geografia: técnicas de Campo e laboratório. São Paulo: Oficina de Textos, 2009.

Jarvis, A., H.I. Reuter, A. Nelson, E. Guevara, 2008, Hole-filled SRTM for the globe Version 4, available from the CGIAR-CSI SRTM 90m Database. Disponível: <srtm.csi.cgiar.org> acesso: 31. Out. 2016

LEVIGHIN, S. C.; VIADANA, A. G. Perfis Geo-ecológicos como técnica para os estudos das condições ambientais. Sociedade \& Natureza. Uberlândia, 14 e 15 (26 a 29), p. 5-14, 2002/2003.

MASCARENHAS, A. L. S.; VIDAL, M. R. O Uso do Perfil Geoecológico para a Representação da Paisagem: Uma Metodologia Útil em Campo?. In: XV Simpósio Brasileiro de Geografia Física Aplicada, 2013, Vitória-ES. Anais dos Trabalhos Científicos. Vitória: Departamento de Geografia. CCHN. UFES., 2013. v. 1. p. 754-761.

MONTEIRO. C. A. F. Geossistema: a história de uma procura. São Paulo, Contexto, 2000.

RICARDO, C. A. (Org.). Povos Indígenas no Brasil. São Paulo: CEDI, 1985.

RODRIGUEZ, J. M. M. Análise e síntese de abordagem geográfica de pesquisa para o planejamento ambiental. Revista do Departamento de Geografia de FFLCH/USP. São Paulo: v.9. 1994.

RODRIGUES; J. M. M.; SILVA, E.V.; CAVALCANTI, A. P.B. Geoecologia das paisagens: uma visão geossistêmica da análise ambiental.Fortaleza, EDUFC, 2004.

FERNANDES, R.F. Educação escolar Kyikatêjê: novos caminhos para aprender e ensinar. 2010. $215 f$. Dissertação (Mestrado em Direito) - Instituto de Ciências Jurídicas- ICJ, Universidade Federal do Pará, Belém, 2010. 